\title{
Editorial
}

El nuevo milenio y la presente década nos ha traído múltiples acontecimientos, diversas perspectivas, menos certezas, mayores incertidumbres, más inseguridades y nuevos interrogantes.

En Latinoamérica los cambios políticos han sido grandes en este periodo. La izquierda ha surgido en varios países, pero de distinta forma. La derecha se ha mantenido en otros, pero con apuestas distintas. Esos cambios políticos han repercutido en la economía y en la vida cotidiana. Varios países latinoamericanos han enfrentado intentos separatistas, otros han podido salir momentáneamente de las crisis económicas, pero aún están en problemas, la brecha entre los ricos y los pobres en nuestro continente es cada vez mayor, lo cual demuestra la desigualdad social y la paulatina concentración del poder.

A este panorama que no es muy alentador, se suma la crisis de los paradigmas académicos. "Los paradigmas, decía Kuhn, proporcionan a todos los fenómenos, excepto las anomalías, un lugar determinado por la teoría en el campo de visión de los científicos" ${ }^{\prime \prime}$. Lo cierto es que desde hace más de una década las ciencias sociales -y esta

${ }^{1}$ KUHN, Thomas, La Estructura de las Revoluciones Cientificas, México, Fondo de Cultura Económica, 1971, pág. 157. 
percepción puede generar controversia- no cuentan con nuevas revoluciones científicas que nos ayuden a explicar ese mundo latinoamericano y colombiano que estamos viviendo.

Esta situación social y científica es caótica, y por eso mismo puede aprovecharse creativamente. Sin duda, las nuevas teorías sociales y las que tienen que ver con la comunicación, han intentado explicar la dinámica de una sociedad distinta como la que tenemos hoy.

Ese esfuerzo no siempre ha sido exitoso, pero en ocasiones ha sido legítimo porque los conceptos se han ido construyendo desde las vivencias y realidades de los sujetos, en relación con las interpretaciones de los teóricos. Es decir, quizá este sea el momento para que la brecha entre "lo científico" y "lo social" no exista, o por lo menos, sea cada vez menor.

Un gran maestro que hace poco nos dejó, como lo fue Orlando Fals Borda, decía hace más de una década: "Hoy, para fortuna nuestra, no sabemos para dónde vamos, y avanzamos porque estamos perdidos y nos vemos obligados a usar esa brújula que es la Investigación Acción. Antes pensábamos que la historia era un bus que llevaba a la Nueva Jerusalén; hoy vemos más claro: la historia es un bus que no sabe para dónde va... Hoy los investigadores están más atentos e interesados en estar al lado del pueblo que en precederle. La confesión de que no sabemos para dónde vamos pero que estamos ahí, hombres y mujeres con la gente que lucha, me parece un paso irreversible"2

La primera invitación que le hacemos a nuestros lectores es a que pensemos si lo que estamos trabajando tiene

${ }^{2}$ FALS, Orlando, Participación Popular: Retos del futuro, Bogotá, Icfes, lepri, Colciencias, 1998, pág. 8. como eje la vida social, y si a su vez, los parámetros que usamos para esas lecturas realmente corresponden a esas realidades. La segunda invitación es frente a nuestra revista MEDIACIONES, les pedimos que lean esta edición número ocho y evalúen si los ensayos que les presentamos están del lado de la gente, como dijo Orlando Fals Borda, o si, al menos, pretenden cerrar la brecha descrita anteriormente.

Los trabajos que presentamos en este número son los siguientes:

Adriana Ángel en el documento Investigación en comunicación: ¿con base en la cultura o en la economía?, analiza la importancia de articular los planteamientos de los estudios culturales y de la economía política de la comunicación para comprender los fenómenos mediáticos actuales, a partir de las dicotomías: orden simbólico / orden social, hegemonía / ideología, y representación simbólica / representación social.

Televisión y género: un análisis desde la perspectiva de los niños y las niñas, escrito por Elvia Vargas, Ángela Rojas y Paola Balanta, presenta los resultados parciales de una investigación interesada en establecer conocimiento acerca del género que están adquiriendo los niños y las niñas a partir de los hábitos de consumo televisivo; este documento presenta las interpretaciones de género que realizaron los niños y las niñas de sus programas preferidos, evidenciando fuertes estereotipos de género y actitudes sexistas.

La geografía política de los espacios, es una reflexión teórica de Gonzalo Ortiz quien sugiere que a partir de la comprensión de la génesis del Estado y sus diferentes formas de capital, los discursos, la soberanía y la legislación, es posible comprender los mecanismos de poder 
que determinan la posición de los agentes dentro del espacio social y en la geopolítica planetaria.

Ethna Romero nos presenta el documento La televisión en el escenario educativo, donde examina la relación entre televisión y educación, así como sus múltiples conflictos, potencialidades, apuestas éticas y retos, en relación con las prácticas educativas, los usos y el consumo de las industrias culturales.

Comunicación para el desarrollo, es el aporte de Gladys Daza, quien hace un importante recorrido por la evolución que ha tenido el campo de la comunicación para el desarrollo en el contexto latinoamericano, el quehacer investigativo de diferentes actores y los retos que exige la construcción de conocimiento en este sentido.

Elssy Moreno, Ibeth Molina, Gonzalo Ortiz y César Rocha, en el artículo titulado: La construcción del desarrollo desde abajo, plantea los resultados finales de un proyecto de investigación participativa, donde un proceso comunicativo y las redes sociales pueden aportarle a la construcción de capital social y desarrollo en dos municipios colombianos.

Vladimir Sánchez, en el artículo Semiosis y cultura: análisis desde la poesía, el arte y la publicidad, hace una una reflexión a la publicidad, la Literatura y el arte, como artificios que desde la significación abordan los grandes problemas de la humanidad y que a su vez, edifican y se alimentan de múltiples contenidos culturales.

\section{El lugar de la variación en el habla y en el discurso, de} María Cristina Asqueta, presenta las bases teóricas de la segunda etapa de una investigación que estudia los aspectos gramaticales y discursivos en el uso lingüístico, manifestado por los jóvenes universitarios bogotanos, a partir de una visión fundamentada en los estudios del estructuralismo y de la pragmática, aplicados de manera complementaria.

Finalmente, Gonzalo Rubiano nos presenta el texto: Expresiones verbales en torno al campo de la violencia que vivencian los habitantes de calle, quien analiza las expresiones de la jerga de los habitantes de calle y la creación léxica, a partir de las palabras, que trascienden el discurso y colman de sentido las realidades de esta población. 


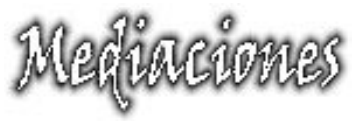

\section{Bibliografía}

FALS, Orlando, Participación Popular: Retos del futuro, Bogotá, Icfes, lepri, Colciencias, 1998.

KHUN, Thomas, La Estructura de las Revoluciones Científicas, México, Fondo de Cultura Económica, 1971. 